\title{
A high-throughput system for boron microsublimation and isotope analysis by total evaporation thermal ionization mass spectrometry
}

\author{
Yi-Wei Liu ${ }^{1 *}$, Sarah M. Aciego', Alan D. Wanamaker Jr. ${ }^{2}$ and Bryan K. Sell ${ }^{1}$ \\ ${ }^{1}$ Earth and Environmental Sciences, University of Michigan, 1100 N. University Avenue, Ann Arbor, MI 48109, USA \\ ${ }^{2}$ Department of Geological and Atmospheric Sciences, lowa State University, Ames, IA 50011, USA
}

RATIONALE: Research on the ocean carbon cycle is vitally important due to the projected impacts of atmospheric $\mathrm{CO}_{2}$ on global temperatures and climate change, but also on ocean chemistry. The direct influence of this $\mathrm{CO}_{2}$ rise on the seawater $\mathrm{pH}$ can be evaluated from the boron isotopic composition in biogenic carbonates; however, conscientious laboratory techniques and data treatment are vital in obtaining accurate and precise results. A rapid-throughput boron purification and Total Evaporation Thermal Ionization Mass Spectrometry method was developed for high accuracy and precision boron isotopic analysis for small (ng) sample sizes.

METHODS: An improved microsublimation method, in which up to 20 samples can be processed simultaneously under identical temperature conditions, was developed. Several tests have confirmed the viability of this technique. First, seawater and Porites coral samples were processed with $\mathrm{H}_{2} \mathrm{O}_{2}$ and the results compared with those obtained using microsublimation; second, the impact of various sublimation times was evaluated; and third, quantitative recovery was assessed using standard addition.

RESULTS: Microsublimation provides a valid method for the quantitative recovery and separation of boron from both major elements and organic matter under low-blank conditions. The close agreement of our results with published values validates the accuracy of the measurements. The isotopic ratio for SRM 951a boric acid isotopic standard was $4.0328 \pm 0.0054(2 \mathrm{STD}, \mathrm{n}=25)$. The reproducibility of boron isotopic composition for standards including AE121, IAEA B-1 and an in-house coral standard UM-CP1 was $\pm 0.68 \%$ ( 2 STD, $\mathrm{n}=15), \pm 1.12 \%$ ( 2 STD, $\mathrm{n}=24)$, and $\pm 1.17 \%$ (2 STD, $\mathrm{n}=14$ ), respectively. The sample sizes were $<1 \mathrm{ng}$ for each measurement.

CONCLUSIONS: The developed method for preparing and measuring boron isotopic values in a variety of carbonate materials should facilitate the reconstruction of past ocean $\mathrm{pH}$ conditions with decadal-scale resolution. Copyright $($ ) 2013 John Wiley \& Sons, Ltd.

Boron has two naturally occurring stable isotopes, ${ }^{10} \mathrm{~B}(19.82 \%)$ and ${ }^{11} \mathrm{~B}(80.18 \%) .{ }^{[1]}$ The distribution of these two isotopes $\left(\delta^{11} \mathrm{~B}\right.$, defined as $\left.\delta^{11} \mathrm{~B}=\left[\frac{\left(\frac{11_{\mathrm{B}}}{10_{\mathrm{B}}}\right)_{\text {sample }}}{\left(\frac{11_{\mathrm{B}}}{10_{\mathrm{B}}}\right)_{\text {SRM } 951 \mathrm{a}}}-1\right] \times 1000(\% \mathrm{o})\right)$ in various geological samples can be used to explore natural processes such as the extent of water-rock/soil interactions or weathering processes, ${ }^{[2-4]}$ airborne anthropogenic emissions, ${ }^{[5]}$ clay mineral formation in soils at the soil-water-plant scale, ${ }^{[6]}$ fluid transfer across tectonic subduction zones, ${ }^{[7]}$ and seawater $\mathrm{pH}$ variations. ${ }^{[8-12]}$

One of the most widely applied applications of boron isotopes in climate and aqueous chemistry is in determining the historical record of $\mathrm{pH}$ in seawater. Because direct measurements of seawater $\mathrm{pH}$ prior to 1980 are sparse, the actual influence of the anthropogenic rise in atmospheric $\mathrm{CO}_{2}$ on the $\mathrm{pH}$ of seawater is still largely undetermined.

\footnotetext{
* Correspondence to: Y.-W. Liu, Earth and Environmental Sciences, University of Michigan, 1100 N. University Avenue, Ann Arbor, MI 48109, USA.

E-mail: liuyiwei@umich.edu
}

Reliable proxies of seawater $\mathrm{pH}$ during the Industrial Revolution and from recent millennia and into deep geologic time are few, but the $\delta^{11} \mathrm{~B}$ values derived from biogenic carbonates (e.g., corals, brachiopods, and foraminifera) have provided important constraints on ancient $\mathrm{pH}$ levels. ${ }^{[8,11,13]}$

The dominant aqueous species of boron in seawater are $\mathrm{B}(\mathrm{OH})_{3}$ and $\mathrm{B}(\mathrm{OH})_{4}^{-}$. The relative proportion of these two species in seawater is a function of $\mathrm{pH}$ and can be described as:

$$
\mathrm{B}(\mathrm{OH})_{3}+\mathrm{H}_{2} \mathrm{O} \rightleftharpoons \mathrm{B}(\mathrm{OH})_{4}^{-}+\mathrm{H}^{+}
$$

At low $\mathrm{pH}$, boron exists as $\mathrm{B}(\mathrm{OH})_{3}$ in solution, and, conversely, at high $\mathrm{pH}$, it exists as $\mathrm{B}(\mathrm{OH})_{4}^{-} \cdot{ }^{[14]}$ The governing reaction for isotope exchange between these two species is:

$$
{ }^{10} \mathrm{~B}(\mathrm{OH})_{3}+{ }^{11} \mathrm{~B}(\mathrm{OH}){ }_{4}^{-} \rightleftharpoons{ }^{11} \mathrm{~B}(\mathrm{OH})_{3}+{ }^{10} \mathrm{~B}(\mathrm{OH})_{4}^{-}
$$

The stable isotope ${ }^{11} \mathrm{~B}$ is enriched in $\mathrm{B}(\mathrm{OH})_{3}$ compared with $\mathrm{B}(\mathrm{OH})_{4}^{-}$, and the combination of Eqns. (1) and (2) can be used to determine the distribution of the two boron species and the isotopic composition of each for a given $\mathrm{pH}$. The boron isotopic composition in the ocean is relatively constant over this time period because the residence time of seawater boron 
is about 14 million years, ${ }^{[15]}$ and the average seawater $\delta^{11} \mathrm{~B}$ value is $39.61 \%{ }^{[16]}$ At low $\mathrm{pH}, \mathrm{B}(\mathrm{OH})_{3}$ is dominant and therefore the $\delta^{11} \mathrm{~B}$ value of $\mathrm{B}(\mathrm{OH})_{3}$ is equal to the isotopic composition of the total dissolved boron in seawater $(39.61 \%)$. In contrast, the isotopic composition of $\mathrm{B}(\mathrm{OH})_{4}^{-}$is dominant in seawater and equal to the isotopic composition of the total dissolved boron at high $\mathrm{pH}$. In addition, the $\delta^{11} \mathrm{~B}$ value of $\mathrm{B}(\mathrm{OH})_{3}$ is about $20 \%$ higher than that of $\mathrm{B}(\mathrm{OH})_{4}^{-}$at any $\mathrm{pH}$ at equilibrium, based on a constant fractionation factor $(\alpha)$. This boric acid-borate fractionation number was defined as $\alpha \equiv \frac{\left(\frac{11 \mathrm{~B}}{1 \mathrm{D}_{\mathrm{B}}}\right)_{\text {boric acid }}}{\left(\frac{11 \mathrm{~B}_{\mathrm{B}}}{\mathrm{I}_{\mathrm{B}}}\right)_{\text {borate }}}$, and two empirical and analytical values have been suggested in seawater: (1) $\alpha=1.0194$, a theoretical result of Kakihana et al. ${ }^{[17]}$ that has been applied widely in paleo-reconstructions, ${ }^{[13,17,18]}$ and (2) $\alpha=1.0246$, which was empirically obtained from Klochko et al.$^{[19]}$ and is considered to better describe the present distribution of the two boron species in nature. ${ }^{[9,19,20]}$ During crystal growth, marine carbonates will primarily incorporate $\mathrm{B}(\mathrm{OH})_{4}^{-}$into the carbonate structure so that biogenic carbonates such as coral and foraminifera have $\delta^{11} \mathrm{~B}$ values that will coevolve with ambient seawater $\mathrm{pH}$ and therefore can be used to reconstruct ancient seawater $\mathrm{pH}$ values. ${ }^{[11,12,21,22]}$ However, due to biological adjustments to the environment, species-specific fractionation factors and transfer functions may be more appropriate than the $\alpha$ values described above. ${ }^{[18,23-28]}$

A precise and accurate measuring technique is critical because modern ocean $\mathrm{pH}$ changes of between 0.1 to $0.5 \mathrm{pH}$ units can occur, ${ }^{[29]}$ which translate into changes of $\delta^{11} \mathrm{~B}$ values of 1 to $4 \%$. Most aragonite skeletal structures have relatively low boron concentrations; ${ }^{[12]}$ hence an ideal analytical technique would allow small sample sizes (several ng or less) to be processed in order to produce highly resolved (annual to decadal) estimates of $\mathrm{pH}$.

Four different methods have been employed to measure boron isotope ratios: (1) Secondary Ion Mass Spectrometry (SIMS) ${ }^{[30,31}$ (2) Positive Ion Thermal Ionization Mass Spectrometry (PTIMS); ${ }^{[32-34]}$ (3) Negative Ion Thermal Ionic Mass Spectrometry (NTIMS); ; ${ }^{[12,14,35,36]}$ and (4) Multi-collector Inductively Coupled Plasma Mass Spectrometry (MC-ICPMS). ${ }^{[9,37]}$ SIMS is an in situ approach that is appropriate for small sample sizes and it appears to be the most promising technique for high-resolution temporal records of $\mathrm{pH}$. However, seasonal or annual variation of $\mathrm{pCO}_{2}$ in seawater will induce changes in seawater $\mathrm{pH}$ of 0.2 to 0.4 units or 1.5 to $3.5 \%$ in the $\delta^{11} \mathrm{~B}$ values of carbonates. ${ }^{[11]}$ Because the typical internal precision of SIMS is $1.2 \%{ }^{[30]}$ this in situ analytical method might be more appropriate for longer time scale paleoclimate studies or time frames with large $\mathrm{pH}$ variations.

PTIMS ionizes the boron as $\mathrm{Cs}_{2} \mathrm{BO}_{2}$ that is formed by mixing a Cs-bearing solution with the samples in the preparation procedure, resulting in a stable beam for measurement with low boron isotope fractionation. The combination of stable beam and low fractionation results in an analytical precision of the order of $\pm 0.2 \%{ }^{[32]}$ The PTIMS method requires $>250 \mathrm{ng}$ of boron, purified to remove both alkali ions and organic material. Despite the large sample requirements, PTIMS has been used for coral studies; ${ }^{[33,34]}$ however, negative polarity thermal ionization is required for smaller samples. NTIMS ionizes boron as the negative ion
$\mathrm{BO}_{2}^{-}$, and the presence of natural matrix salts (e.g. seawater and carbonate) can increase the ionization efficiency to up to two orders of magnitude higher than that of PTIMS. ${ }^{[12,14,35,36]}$ The higher ionization efficiency reduces the amount of sample required ( 1 ng), but, because instrumental mass fractionation occurs between the dominant ${ }^{11} \mathrm{BO}_{2}^{-}$and ${ }^{10} \mathrm{BO}_{2}^{-}$species, triplicate or more analyses are required for accurate, precise results. ${ }^{[18]}$ Therefore, the standard NTIMS approach requires 3 to 6 ng per sample. Foster et al. ${ }^{[36]}$ reported an improved method for small samples $(<1 \mathrm{ng})$, Total Evaporation NTIMS (TE-NTIMS), which minimizes the instrumental mass fractionation and maximizes the sample signal by analyzing samples from beginning to exhaustion. Both NTIMS methods result in typical errors of $<0.5 \%$. . $^{[1,18,36]}$

Recently, boron isotopic ratios have also been measured by MC-ICPMS with precision comparable with that of PTIMS on sample sizes of 15 to $30 \mathrm{ng}^{[9,37]}$ One of the drawbacks to the MC-ICPMS method has been the long wash out time between samples required to eliminate residual boron in the sample introduction system (i.e. memory). In order to eliminate this memory effect these latest studies applied two methods: injection of ammonia gas $^{[38]}$ and high efficiency nebulization (d-DIHEN). ${ }^{[39]}$ In either case, the sample size requirements are still too large to precisely or accurately (because of blank issues) measure samples $<5 \mathrm{ng}$ in size. Ni et al. ${ }^{[37]}$ explored a side-by-side comparison of MC-ICPMS and NTIMS techniques and determined that organic materials probably bias the boron isotopic results in NTIMS, which may explain the deviations in results between laboratories. Because boron isotope analysis by MC-ICPMS requires boron purification, and the organic materials may result in inaccurate boron measurements in TIMS, chemical treatments are required for both NTIMS and MC-ICPMS analysis.

Many methods have been reported for the purification of boron from aqueous samples, including solvent extraction, chelation, chromatographic separation, conversion into gaseous methyl borate or boron fluoride, and ion exchange/ B-specific resin. ${ }^{[40]}$ The conventional method for purifying boron from alkaline matrix ions and organic materials is ion-exchange column chemistry. B-specific resin, Amberlite IRA-743, is widely used to separate boron from matrix materials. ${ }^{[9,32,37]}$ However, the blank increases as a result of the reagents used during the column procedure and isotopic fractionation may occur in the ion-exchange process. ${ }^{[14,36]}$ An alternative way to purify boron is the microsublimation technique, developed by Gaillardet et al., ${ }^{[41]}$ which separates boron without any isotope fractionation. Wang et al. ${ }^{[42]}$ modified the method and showed that, with small modifications to the sublimation processing, no reagents or ion-exchange resins are required in the process. Thus, microsublimation is a promising method for the purification of boron (blank sensitive) samples that are extremely small (of the order of several ng).

Here we report a new approach that applies microsublimation and TE-NTIMS measurement to achieve highly precise and accurate boron isotopic analysis for small samples (boron $<1 \mathrm{ng}$ ). We have developed a microsublimation method modified from those of Gaillardet et al. ${ }^{[41]}$ and Wang et al. ${ }^{[42]}$ in order to process more samples (up to 20 per hotplate) with excellent reproducibility. 


\section{EXPERIMENTAL}

\section{Laboratory conditions, reagents, and labware}

All chemical separation and sample handling were performed under ISO 4 (class 10) laminar flow hoods within an ISO 7 (class 10,000) clean room of the Glaciochemistry and Isotope Geochemistry Laboratory in the Department of Earth \& Environmental Sciences at the University of Michigan (Ann Arbor, MI, USA). The air supply to the clean room is purified by boron-free ultra-low-penetration air (ULPA) filters with polytetrafluoroethylene (PTFE) backing in both the clean and the machine room. Ultra-pure reagents were used throughout the chemistry steps: reagents $(\mathrm{HCl}$, $\mathrm{HNO}_{3}, \mathrm{HF}$, and $\mathrm{H}_{2} \mathrm{O}_{2}$ ) were either Fisher Scientific Optima (Thermo Fisher Scientific, Hudson, NH, USA) or distilled in Savillex (Eden Prairie, MN, USA) DST 1000 distillation units in order to maintain ultra-low blanks. Water was first purified using a Super-Q (SQ) Millipore system (EMD Millipore, Corp., Billerica, MA, USA) at 18.2 M $\Omega$ and then distilled again before use. The reagent boron blanks were all less than $1 \mathrm{ppb}$, which was measured on a Varian (Palo Alto, CA, USA) 820 MS plasma-source quadrupole mass spectrometer housed in the Element Measurement Facility at the State University of New York, Oswego (Oswego, NY, USA). With a maximum of $50 \mu \mathrm{L}$ reagent used for each sample and $1 \mu \mathrm{L}$ of sample loaded onto a filament, the blank introduced was lower than $1 \mathrm{pg}$ for each measurement and was thus negligible.

Savillex perfluoroalkoxy (PFA) labware was cleaned in a three-step cleaning procedure: (1) submerged overnight in $7 \mathrm{~N}$ distilled $\mathrm{HNO}_{3}$, (2) submerged overnight in $6 \mathrm{~N}$ distilled $\mathrm{HCl}$, and (3) filled with distilled concentrated $\mathrm{HNO}_{3}$ for 3 days; all steps performed at $90{ }^{\circ} \mathrm{C}$. Between steps the labware beakers were triple rinsed with SQ water. After being cleaned, the labware was dried in a boron-free filtered air drying cabinet (ProPlastic Technology, Chandler, AZ, USA).

\section{Standards and samples}

A range of elemental standard solutions was used to evaluate the success of the sublimation and mass spectrometric techniques. Solution standards included certified boric acid standards NIST SRM 951a (NIST, Gaithersburg, MD, USA) (a replacement for NIST SRM 951), AE-121 (BAM, Berlin, Germany) and a west Mediterranean seawater standard, IAEA B-1 (IAEA, Vienna, Austria). In order to assess the long-term analytical precision, we processed a large Porites coral sample to be used as an in-house working standard for marine aragonite carbonate (UM-CP1). The coral was live-collected off the coast at Rodriguez Key, Florida, USA, in 1990. The coral was treated with sodium hypochlorite after collection and a pristine segment (approximately $2 \mathrm{~g}$ ) was powdered, rinsed three times with SQ water and dried at room temperature. For standard or seawater sample solutions, the samples were diluted to provide a concentration of $750 \mathrm{ppb}$ boron in $1.7 \mathrm{~N} \mathrm{HCl}$. The carbonate powders were dissolved in $1.7 \mathrm{~N} \mathrm{HCl}$ to a concentration of $750 \mathrm{ppb}$.

Finally, we assessed the reproducibility of this technique by measuring a series of natural seawater samples from a bivalve culture experiment in the Gulf of Maine, USA. ${ }^{[43]}$ Natural seawater - seasonally varying in salinity, $\mathrm{pH}$ and temperature - was pumped into the Darling Marine Center
(Walpole, Maine, USA) from an average depth of $10 \mathrm{~m}$. Samples were directly collected from the experimental tanks approximately biweekly (January 2010 to August 2010) and then were filtered through a $0.45-\mu \mathrm{m}$ filter $\left(\mathrm{Cameo}^{\mathrm{TM}} 30 \mathrm{GN}\right.$ Nylon prefilter; GE Osmonics Inc., Minnetonka, MN, USA) and refrigerated at $\sim 4{ }^{\circ} \mathrm{C}$.

Because the Darling Marine Center pumps water from the Damariscotta River, a tidewater estuary slightly inland from the central coastal of the Gulf of Maine, an additional seawater sample that was removed from the influences of the estuary was collected for comparison. The Gulf of Maine surface seawater sample was collected at $44^{\circ} 26^{\prime} 9.829^{\prime \prime} \mathrm{N}$, $67^{\circ} 26.0^{\prime} 18.045^{\prime \prime} \mathrm{W}$ off Jonesport, Maine, on November 23, 2009. In order to assess possible factors that might affect the boron isotopic composition, it is useful to track the boron isotopic ratio in different sources (freshwater versus full marine conditions). The collection and measurement of boron isotopic composition in seawater from the culture tanks and the open ocean environment can be used to evaluate whether the culture experiments were representative of the natural marine environment.

\section{Boron separation by microsublimation}

\section{Principles}

The microsublimation technique for boron purification is based on the tendency of boron to sublimate at a temperature and pressure where alkaline matrices and organic matter remain in solution or solid form. ${ }^{[41]}$ The technique design utilized a 5-mL conic bottom Savillex PFA vial. The vial is set upside-down so that the cap can be heated, causing the boron to sublimate and then condense onto a cooler surface at the conical point in the bottom of the vial. In the experiments of Gaillardet et al., ${ }^{[41]}$ the flat bottom (the cap of the vial) was heated to $60-65^{\circ} \mathrm{C}$ for $12 \mathrm{~h}$ with aluminum foil wrapped on the lower part of the device. The drawback of this design lies in the difficulty of controlling and maintaining stable and consistent heating and cooling conditions, as nonreproducible heating and cooling conditions may result in variable sample recoveries. Furthermore, this sublimation process was conducted after conventional column chemistry techniques, which may cause isotopic fractionation. Wang et al. ${ }^{[42]}$ modified the above technique by performing a sublimation process, which included an additional fan for cooling but did not require prior resin use. Even with these modifications, inconsistent heating conditions may still occur between different vials, especially at the conical top of the vials. Therefore, we designed and fabricated microsublimation block sets to ensure that all samples were exposed to the same thermal conditions during this process.

In this study, samples were dissolved and diluted to a concentration of about $750 \mathrm{ppb}$ in $1.7 \mathrm{~N} \mathrm{HCl}$. An aliquot of about $20 \mu \mathrm{L}$ was weighed and about $30 \mu \mathrm{L}$ of standard SRM 951a was added, to evaluate the boron concentration using the standard addition technique. Another 50- $\mu \mathrm{L}$ sample solution droplet was loaded onto the cap of a 5-mL conic bottom PFA vial (Savillex). The vial was then closed firmly and placed conic-bottom-side up in our machined sublimation blocks and a cooling block placed on top (Fig. 1). The heating and cooling blocks are both coated in a proprietary thermoplastic material. The bottom heating 

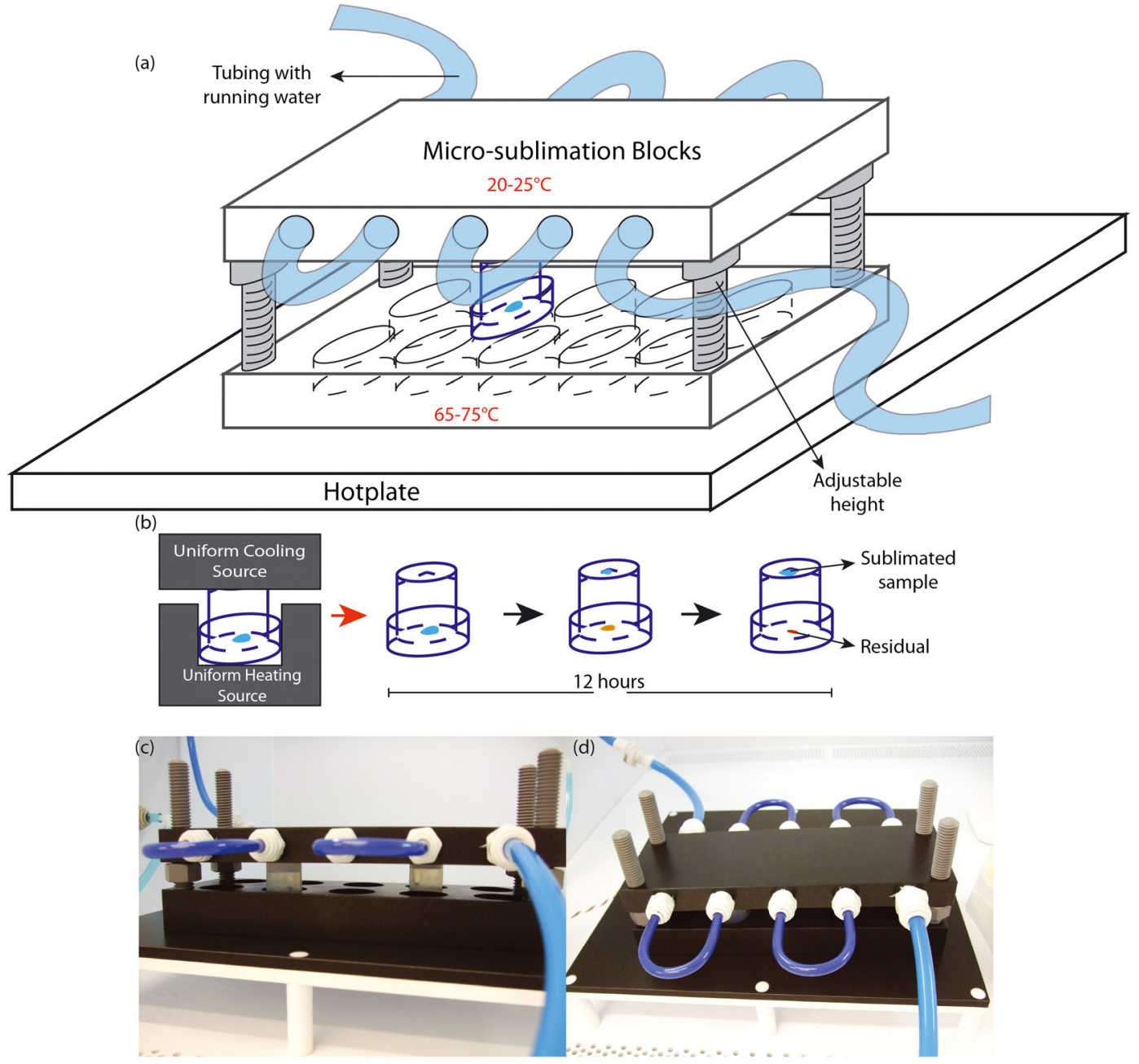

Figure 1. Illustration of the microsublimation device used in this study. The cartoon (a) shows the generalized microsublimation design. The illustration (b) shows the uniform heating and cooling of the vial containing a sample. Samples are loaded onto the cap with 5-mL conic bottom vial in an upside-down position. After a 12-h sublimation, boron is separated and condensed at the tip of the vial. Photographs (c) and (d) are the sublimation block sets.

blocks were machined to precisely fit the tops of the 5-mL conic beakers. Water from the in-house deionized chilled water system flows through the upper part of the cooling coil block through machined channels connected by polyvinyl chloride (PVC) tubing so that the temperature can be maintained at about $23{ }^{\circ} \mathrm{C}$. The cooling coil block rests on threaded chlorinated polyvinyl chloride (CPVC, a thermoplastic that has excellent corrosion resistance at high temperature), such that no vibration from water flow disturbs the drops. In addition to supporting the cooling block, the low thermal conductivity CPVC prevents heat transfer to the upper cooling block, is corrosion resistant, and can withstand temperatures up to $90{ }^{\circ} \mathrm{C}$. The coated stainless steel design of our heating blocks provides a uniform heating and cooling surfaces for the sublimation, which facilitates complete boron evaporation (Fig. 1(b)). In order to process large numbers of samples, we designed the heating and cooling blocks to process 10 separate samples at a time and up to 20 per hotplate.

Once sample vials had been loaded into the vials and placed on the microsublimation blocks, they were heated at 70 to $74{ }^{\circ} \mathrm{C}$ for $12 \mathrm{~h}$. The sublimate boron sample was then split in half and one part was used to test the yield using standard addition while the other half of the solution was used for isotopic analysis by TE-TIMS. To confirm the ability of our method to purify boron without organic interferences or isotopic fractionation, two additional steps were tested: $\mathrm{H}_{2} \mathrm{O}_{2}$ treatment and $20 \mathrm{~h}$ sublimation time.

\section{Assessment of organic removal: comparison with $\mathrm{H}_{2} \mathrm{O}_{2}$}

In order to assess the performance of the microsublimation blocks in separating the organic matter from the boron sample solution, the in-house standard UM-CP1 and standard seawater IAEA B-1 were processed with and without hydrogen peroxide treatment prior to sublimation. For the hydrogen peroxide test, $30 \% \mathrm{H}_{2} \mathrm{O}_{2}$ and concentrated $\mathrm{HCl}$ were added to dissolve (carbonate) or dilute (seawater) samples to $750 \mathrm{ppb}$ in $1.7 \mathrm{~N} \mathrm{HCl}$ and $10 \% \mathrm{H}_{2} \mathrm{O}_{2}$ and the samples were then placed in an ultrasonic bath for two hours in closed vials. The samples then were uncapped and allowed to decompose and exsolve $\mathrm{O}_{2}$ for $1 \mathrm{~h}$ before being loaded onto 
the caps. Two sublimation periods, 12 and $20 \mathrm{~h}$, were also tested to assess the quantitative sublimation of boron from an organic rich matrix (e.g. Wang et al. ${ }^{[42]}$ ).

\section{Quantitative recovery of boron}

A standard addition method was used to quantify the recovery of the microsublimation method. SRM 951a was added to two sets of standards (UM-CP1 and IAEA B-1) before and after sublimation for each set. The samples were weighed before and after standard addition and microsublimation for concentration calculations. The sample concentrations before and after sublimation can therefore be calculated from the equations based on two end-member mixing model:

$$
\begin{gathered}
{[\mathrm{B}]_{\text {before }}=\frac{[\mathrm{B}]_{\text {SRM 951a }} \times \mathrm{W}_{\text {SRM 951a }} \times\left[\left(\frac{{ }^{11} \mathrm{~B}}{{ }^{10} \mathrm{~B}}\right)_{\text {measured }}-\left(\frac{{ }^{11} \mathrm{~B}}{{ }^{10} \mathrm{~B}}\right)_{\text {SRM 951a }}\right]}{\mathrm{W}_{\text {sample }} \times\left[\left(\frac{{ }^{11} \mathrm{~B}}{{ }^{10} \mathrm{~B}}\right)_{\text {sample }}-\left(\frac{{ }^{11} \mathrm{~B}}{{ }^{10} \mathrm{~B}}\right)_{\text {measured }}\right]}} \\
{[\mathrm{B}]_{\text {after }}=\frac{[\mathrm{B}]_{\text {SRM 951a }} \times \mathrm{W}_{\text {SRM 951a }} \times\left[\left(\frac{{ }^{11} \mathrm{~B}}{{ }^{10} \mathrm{~B}}\right)_{\text {measured }}-\left(\frac{{ }^{11} \mathrm{~B}}{{ }^{10} \mathrm{~B}}\right)_{\text {SRM 951a }}\right]}{50 / 45 \times \mathrm{W}_{\text {sample }} \times\left[\left(\frac{{ }^{11} \mathrm{~B}}{{ }^{10} \mathrm{~B}}\right)_{\text {sample }}-\left(\frac{{ }^{11} \mathrm{~B}}{{ }^{10} \mathrm{~B}}\right)_{\text {measured }}\right]}}
\end{gathered}
$$

$[B]_{\text {before }}$ is the boron concentration with standard added before sublimation, and $[\mathrm{B}]_{\text {after }}$ is the boron concentration with standard added after sublimation. The boron concentration prepared for SRM 951a was $722 \mathrm{ppb}$ in this study. $\mathrm{W}_{\text {SRM 951a }}$ $W_{\text {sample }}$ and $W_{\text {sample' }}$ are the weight of SRM 951a, the original sample solution and the sublimated sample solution, respectively. The ${ }^{11} \mathrm{~B} /{ }^{10} \mathrm{~B}$ ratios are boron isotopic ratios for SRM 951a, the target sample and the mixture solution measured in this study. The 50/45 factor in the calculation for boron concentration after microsublimation results from the removal of alkaline matrix and organic matter residual, which changed the post-sublimation solution mass.

\section{Mass spectrometry, measurement by TE-TIMS}

All measurements were conducted on a TRITON Plus multicollector thermal ionization mass spectrometer (Thermo Electron Corp., San Jose, CA, USA) operating in negative ion mode at the Department of Earth and Environmental Sciences, University of Michigan. Daily gain calibrations were conducted to minimize instrumental uncertainty. A cold trap with liquid nitrogen was used to sustain the main high vacuum source pressure (HV source pressure) between $4 \times 10^{-8}$ and $8 \times 10^{-8}$ mbar, which improved the stability of the environment and reduced possible interferences from water vapor and $\mathrm{CO}_{2}$ in the sample chamber. Venting of the mass spectrometer with ultra-high-purity nitrogen gas and baking of the source between turret exchanges were also implemented to reduce interferences and pump down time.

Samples were loaded onto outgassed single Re filament at 0.8 A current. First $1 \mu \mathrm{L}$ of boron-free synthetic seawater matrix was loaded and dried to facilitate ionization efficiency. The synthetic seawater was made based on the method developed by Kester et al. ${ }^{[4]]}$ A total evaporation method was employed in order to decrease the variability in isotopic measurements caused by different mass fractionation behavior of sample types and load sizes. ${ }^{[36]}$ This technique also reduced the sample size, so that $1 \mu \mathrm{L}$ of sample solution ( $<1 \mathrm{ng}$ boron) was loaded onto the filament following the matrix. The samples were dried down at 2 A current for $15 \mathrm{~s}$ and the filaments were flashed to a dull red color in the center of the filament (about 2.5 A). The loaded samples were then immediately placed into the source chamber, maintained at low humidity with ultra-pure nitrogen gas during sample turret changes.

The samples were preheated to $1200 \mathrm{~mA}$ at a rate of $100 \mathrm{~mA} / \mathrm{min}$ while 600 cycles of (about $10 \mathrm{~min}$ ) baseline were measured. The sample was then gradually heated to $1300 \mathrm{~mA}$ at a rate slower than $30 \mathrm{~mA} / \mathrm{min}$. The ${ }^{35} \mathrm{Cl}$ signal was detected when the filament reached $\sim 800{ }^{\circ} \mathrm{C}$ because of its lower ionization energy and was used for initial source lenses tuning when it increased to about $100 \mathrm{mV}$. To assess the organic interference on mass $42\left({ }^{12} \mathrm{C}^{14} \mathrm{~N}^{16} \mathrm{O}\right)$ mass 26 $\left({ }^{12} \mathrm{C}^{14} \mathrm{~N}\right)$ was also monitored with a secondary electron multiplier (SEM) at the beginning of the heating process because organic matter tends to ionize at a lower temperature than boron. The control masses were then switched to 42 $\left({ }^{10} \mathrm{~B}^{16} \mathrm{O}^{16} \mathrm{O}^{-}\right)$and $43\left({ }^{11} \mathrm{~B}^{16} \mathrm{O}^{16} \mathrm{O}^{-}\right)$after initial tuning of the source lenses. The sample was gradually heated $(10-20 \mathrm{~mA}$ per heating cycle) and the source lenses were optimized between cycles. When the intensity of mass 43 reached 60-70 mV, peak centering was conducted for masses 42 and 43. The total evaporation data acquisition was started when the intensity of mass 42 reached $20 \mathrm{mV}\left(\sim 830-890^{\circ} \mathrm{C}\right)$ and the collection was terminated when the signal dropped to lower than the initial $20 \mathrm{mV}$ intensity. Typical curves for SRM 951a measurement are illustrated in Fig. 2. The detailed cup configuration and method settings are listed in Table 1. The heating slope was $10 \mathrm{~mA}$ /cycle in our method which we found allowed us to achieve maximum intensity of the signal and maintain stability rather than exceed detection limits due to sudden sample exhaustion. To eliminate the interferences from different oxygen isotopic compositions when forming $\mathrm{BO}_{2}^{-}$, mass $45\left({ }^{11} \mathrm{~B}^{16} \mathrm{O}^{18} \mathrm{O}^{-}\right)$was measured. The ratio of mass 45 to

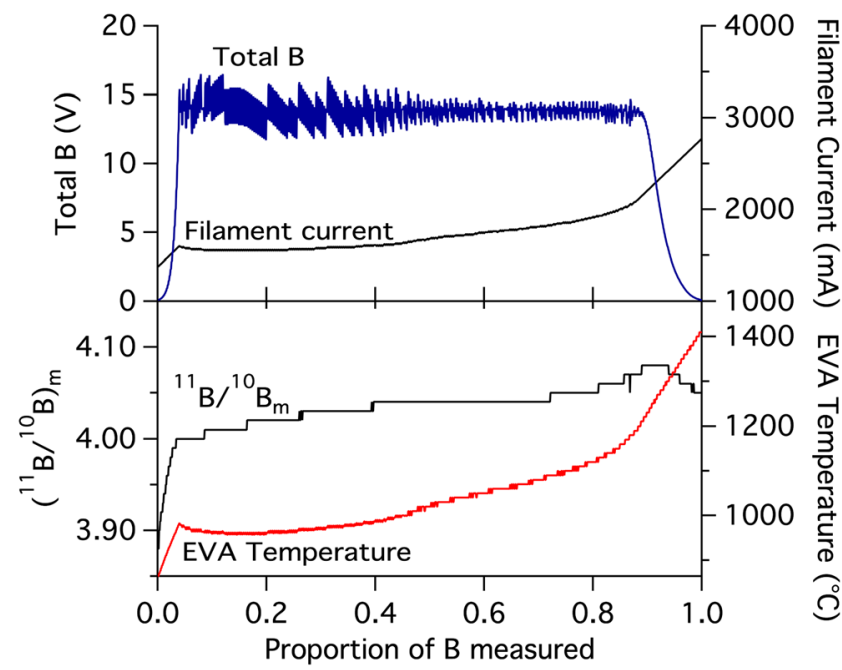

Figure 2. Example ionization curves of the measured boron isotopic ratio, total boron intensity, filament current and filament temperature for SRM 951a by TE-NTIMS on the Thermo Scientific TRITON Plus at the Department of Earth and Environmental Sciences, University of Michigan. 
Table 1. Detailed cup configuration and method settings

\begin{tabular}{|lcl|} 
Faraday cup & Species & \multicolumn{1}{c|}{ Other settings } \\
\hline $\mathrm{C}$ & 42 & Maximum pilot signal: $14 \mathrm{mV}$ \\
$\mathrm{H} 1$ & 43 & Heat slope: $10 \mathrm{~mA} /$ cycle \\
$\mathrm{H} 2$ & - & Intensity offset for stop: 0 \\
$\mathrm{H} 3$ & 45 & Integration time: $8.389 \mathrm{~s}$ \\
\hline
\end{tabular}

43 was used to calculate the oxygen fractionation factor based on the exponential law for mass dependent fractionation, which follows the equations:

$$
\begin{aligned}
& \left(\frac{\mathrm{O}_{18}}{\mathrm{O}_{16}}\right)_{\mathrm{m}}=\left(\frac{\mathrm{O}_{18}}{\mathrm{O}_{16}}\right)_{\mathrm{n}} \times\left(\frac{17.9992}{15.9949}\right)^{\beta} \\
& \text { and } \\
& \left(\frac{\mathrm{O}_{17}}{\mathrm{O}_{16}}\right)_{\mathrm{m}}=\left(\frac{\mathrm{O}_{17}}{\mathrm{O}_{16}}\right)_{\mathrm{n}} \times\left(\frac{16.9991}{15.9949}\right)^{\beta}
\end{aligned}
$$

where the subscripts $\mathrm{m}$ and $\mathrm{n}$ represent the measured isotopic ratio and the ratio of isotope abundances in nature, respectively. The $\beta$ value is the fractionation factor for the measurement. Therefore, by knowing the $\left(\frac{\mathrm{O}_{18}}{\mathrm{O}_{16}}\right)_{m}$ ratio (determined from the ratio of mass 45 to 43), we can obtain a filament-specific ${ }^{17} \mathrm{O} /{ }^{16} \mathrm{O}$ ratio and then subtract this number to correct the $43 / 42\left({ }^{11} \mathrm{~B} /{ }^{10} \mathrm{~B}\right)$ ratios.

All the boron isotopic ratios were normalized to the NIST SRM 951a standard using the $\delta$ notation as:

$$
\delta^{11} \mathrm{~B}=\left[\frac{\left(\frac{{ }^{11} \mathrm{~B}}{{ }^{10} \mathrm{~B}}\right)_{\text {sample }}}{\left(\frac{11 \mathrm{~B}}{{ }^{10} \mathrm{~B}}\right)_{\text {SRM } 951 \mathrm{a}}}-1\right] \times 1000(\% \mathrm{o})
$$

\section{RESULTS}

All the mean values from this study were consistent with the certified or other published values. Slightly higher averages were obtained than in published results using conventional NTIMS techniques.
The results for the boron isotope standards NIST SRM 951a, AE-121, IAEA B-1 and an in-house working standard UM-CP1 are shown in Figs. 3-5. The boron isotopic ratios for the inter-laboratory standards SRM 951a, AE-121 and IAEA B-1 reported in other studies are plotted in Figs. 3 and 4 for comparison. ${ }^{[12,36,45-48]}$ No organic signal was detected after sublimation. A total of 25 SRM 951a samples were measured over 3 months, and the ratio of ${ }^{11} \mathrm{~B} /{ }^{10} \mathrm{~B}_{\mathrm{SRM}} 951 \mathrm{a}$ was $4.0328 \pm 0.0054(1.35 \%$, 2 STD, $\mathrm{n}=25)$. The mean $\delta^{11} \mathrm{~B}$ values of AE-121 and IAEA B-1 were $20.37 \pm 0.68 \%$ (2 STD, $\mathrm{n}=15)$ and $40.60 \pm 1.12 \%$ o (2 STD, $n=24)$, respectively. For the internal standard UM-CP1, the $\delta^{11} \mathrm{~B}$ value was $19.08 \pm 1.17 \%$ o (2 STD, $\mathrm{n}=14$ ).

For the analysis of UM-CP1, the samples were cross-tested both with and without $\mathrm{H}_{2} \mathrm{O}_{2}$ treatment and sublimated for 12 or $20 \mathrm{~h}$. The same testing was also carried out for the IAEA B1 seawater standard, as indicated in the last four data points in Fig. 4(b). These results agree well (with a similar reproducibility to the other boron isotopic standards shown above), regardless whether they were processed with $\mathrm{H}_{2} \mathrm{O}_{2}$ or had a longer sublimation time.

The calculated concentrations before and after microsublimation were $1154 \mathrm{ppb}$ and $1106 \mathrm{ppb}$ for UM-CP1 and $619 \mathrm{ppb}$ and $633 \mathrm{ppb}$ for IAEA B-1.

The $\delta^{11} \mathrm{~B}$ values of seawater from the culture experiment in the Gulf of Maine are shown in Fig. 6. The mean $\delta^{11} \mathrm{~B}$ value was $39.31 \pm 1.73 \%$ o (2 STD, $\mathrm{n}=36$ ).

\section{DISCUSSION}

\section{Accuracy}

Mass 26 was monitored at the beginning of every measurement and no signal $(<2$ counts per second (cps)) was detected, confirming the success of microsublimation for purification from organic materials. The boron isotopic ratios measured by TIMS for SRM 951a fall within a range of 3.98 to 4.04. Our results are similar and consistent with the data from Foster et al., ${ }^{[36]}$ measured using the TE-NTIMS method. This indicates that our analysis can provide externally reproducible boron measurements from extremely

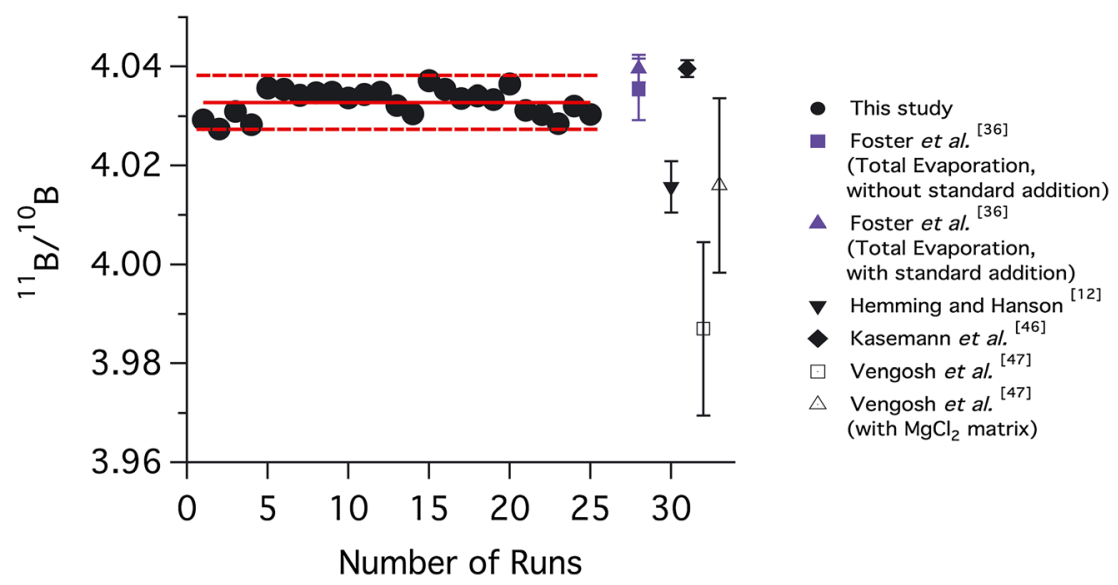

Figure 3. The results of ${ }^{11} \mathrm{~B} /{ }^{10} \mathrm{~B}$ ratio of SRM 951a in this study. Data are shown with solid black circles. Solid red lines represent mean values for different data sets, with two standard deviations shown in dash red lines. Data analyzed by the NTIMS method from previous studies are listed for comparison. 


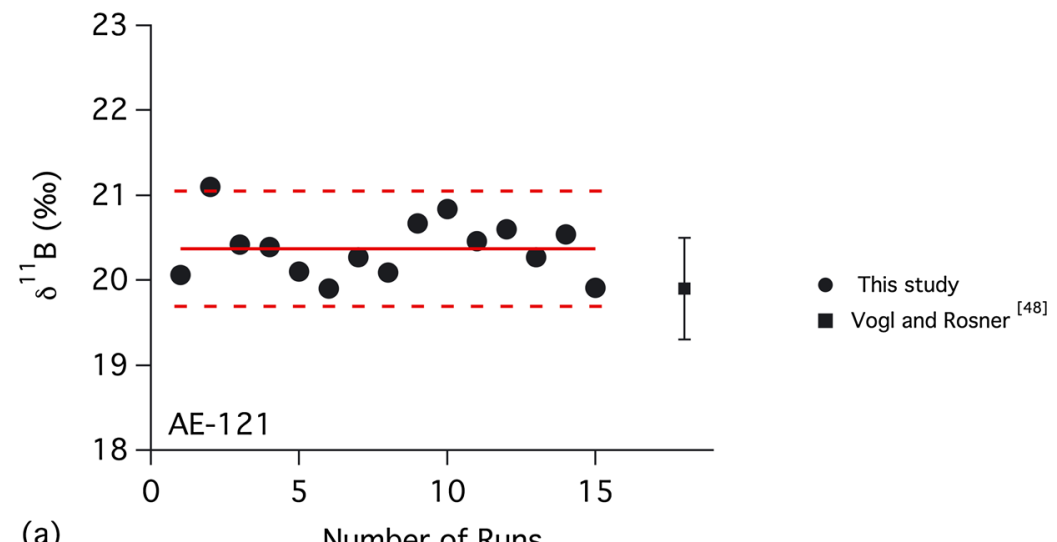

(a)

\section{Number of Runs}

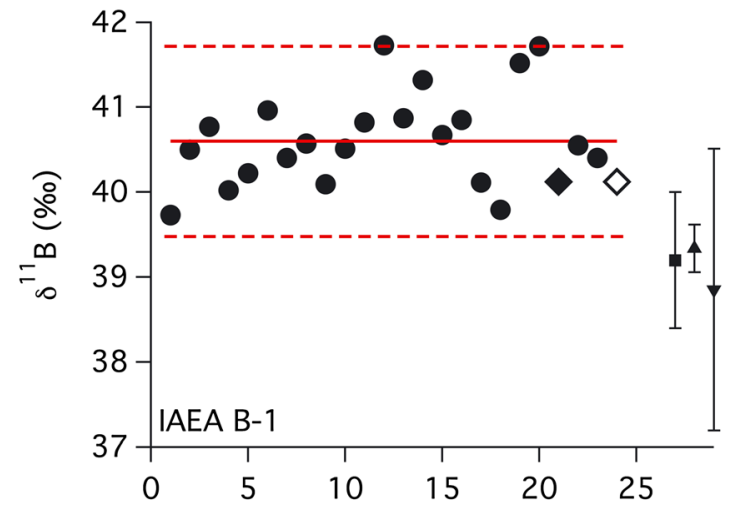

(b)

Number of Runs

$$
\begin{aligned}
& \text { This study } \\
& 12 \text { hours sublimation, } \\
& \text { without } \mathrm{H}_{2} \mathrm{O}_{2} \text { treatment } \\
& 12 \text { hours sublimation, } \\
& \text { with } \mathrm{H}_{2} \mathrm{O}_{2} \\
& 20 \text { hours sublimation, } \\
& \text { with } \mathrm{H}_{2} \mathrm{O}_{2} \\
& \text { - Foster et al. }{ }^{[36]} \\
& \text { Gonfiantini et al. }{ }^{\text {[45] }} \\
& \text { Annette Deyhle } \\
& \text { (GEOMAR, Kiel, Germany) } \\
& \text { Sonia Tonarini } \\
& \text { (Istituto di Geocronologia } \\
& \text { e Geochimica Isotopica del } \\
& \text { CNR, Pisa, Italy) }
\end{aligned}
$$

Figure 4. The $\delta^{11} \mathrm{~B}$ results for standards (a) AE-121 and (b) IAEA B-1. Data analyzed by the NTIMS method from previously published literature are shown for comparison.

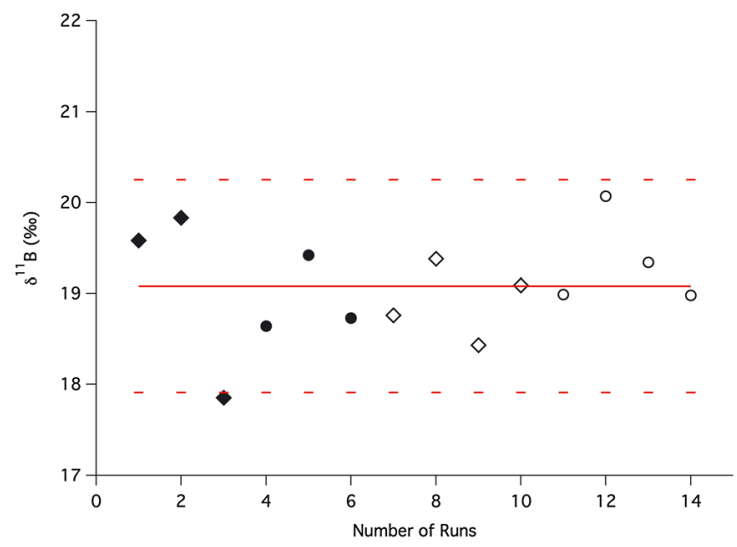

Figure 5. The $\delta^{11} \mathrm{~B}$ values of in-house aragonite carbonate standard UM-CP1. Solid diamonds and circles represent samples with 12-h sublimation time. Open diamonds and circles represent sample with 20-h sublimation time. Diamonds represent samples with $\mathrm{H}_{2} \mathrm{O}_{2}$ treatment.

small samples. Offsets appeared between our ${ }^{11} \mathrm{~B} /{ }^{10} \mathrm{~B}$ ratios and other non-TE-NTIMS data, which might be attributed to laboratory-specific instrumental fractionation. These differences should not affect the $\delta^{11} \mathrm{~B}$ value between laboratories because all the boron isotopic ratios were

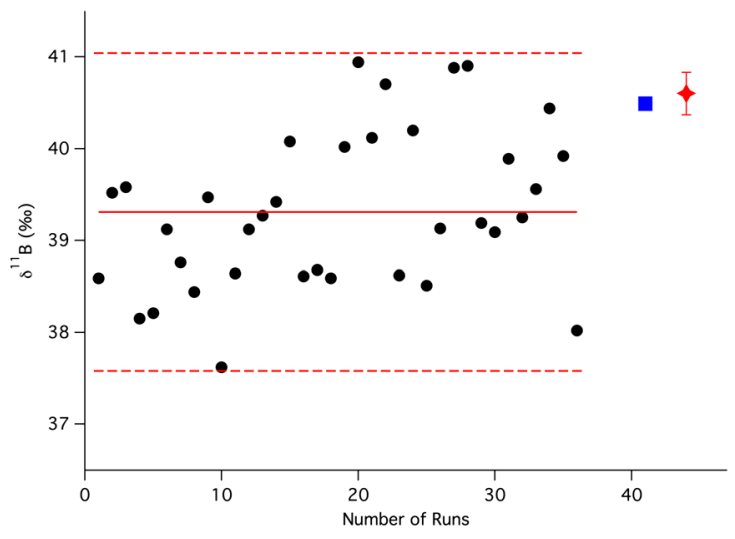

Figure 6. The $\delta^{11} \mathrm{~B}$ values of seawater (black circles) from the culture experiment from the Damariscotta River (Gulf of Maine). The $\delta^{11} \mathrm{~B}$ results from Jonesport (Gulf of Maine) seawater (blue square), and IAEA B-1, with 2 SE from Fig. 3(b) (red star) are plotted for comparison.

normalized to SRM 951a. Based on the results reported here for the two external standards, AE-121 and IAEA B-1, and after comparing these results with those published using both TIMS and MC-ICPMS, we conclude that accurate and reproducible $\delta^{11} \mathrm{~B}$ measurements were achieved in this study. 
Assessment of microsublimation technique: organic removal and recovery

The results of $\mathrm{H}_{2} \mathrm{O}_{2}$ sample treatment for 12 and $20 \mathrm{~h}$ are shown in Fig. 5 and the last four data points in Fig. 4(b). The treatment with $\mathrm{H}_{2} \mathrm{O}_{2}$ oxidizes organic matter adhering to carbonate skeletons such that it has been widely used to eliminate the interferences from organic matter. ${ }^{[23,34,37,49,50]}$ There is no trend or systematic offset between samples with different sublimation time or treatment with $\mathrm{H}_{2} \mathrm{O}_{2}$, indicating that our microsublimation method is highly suitable for recovering boron for isotopic analysis. Based on these experiments, a rapid throughput of 10 to 20 samples was achievable using a 12 -h sublimation period for $50-\mu \mathrm{L}$ sample solutions in $5-\mathrm{mL}$ conic bottom vials.

The boron concentrations of UM-CP1 and IAEA B-1 before and after sublimation are consistent with each other, with standard deviations of $3 \%$ and $1.5 \%$, respectively, and yields better than $97 \%$. The equivalent solution concentrations before and after microsublimation indicate the success of the purification design and the reliability of the data. For UM-CP1, the differences between the calculated solution concentration of $\sim 750 \mathrm{ppb}$ and the concentration of $\sim 1100 \mathrm{ppb}$ obtained by standard addition is due to a higher boron concentration in the powder than our initial assumption of $40 \mathrm{ppm}$. The actual boron concentration in the coral Porites powder UM-CP1 is about 65 ppm, measured by a Varian 820 MS plasma-source quadrupole mass spectrometer.

\section{Reproducibility}

The combination of the warm block on the bottom and the water-cooled coil at the top provides reproducible sample processing for analysis by mass spectrometry. For a variety of standards, including boric acid, seawater and coral, a precision better than 1.4\% (2 STD, $\mathrm{n}>10$ ) was achieved. This precision is comparable with previous TE-NTIMS measurements by Foster et al. and Ni et al. in which precisions of 1.5\% for SRM 951 and $0.8 \%$ for IAEA B-1, and 1.2\%o for their in-house foraminifera standard, were reported, respectively. ${ }^{[36,37]}$ Although the precision of our method is slightly worse than that obtained by MC-ICPMS and P-TIMS, the sample amount required for single measurement is lower than $1 \mathrm{ng}$, which provides the potential to construct highresolution $\mathrm{pH}$ records during modern times, including the Industrial Revolution, and over longer geological timescales.

\section{Boron isotopic composition of seawater for culture experiments}

The preliminary results of boron isotopic composition in tank seawater from the culture experiment in the Gulf of Maine $\left(\delta^{11} \mathrm{~B}=39.31 \%\right.$ ) were about $1.3 \%$ lower than the isotopic ratio in IAEA B-1 $\left(\delta^{11} \mathrm{~B}=40.60 \%\right)$ and in the open ocean sample from the Gulf of Maine $\left(\delta^{11} \mathrm{~B}=40.49 \%\right)$. Since riverine flux is considered to be an important input to balance the global marine boron isotope budget, ${ }^{[15]}$ this offset might be attributed to the influence of river water in the Gulf of Maine with a lower boron isotopic composition. Because the absolute boron isotopic compositions in biogenic carbonate depend on not only the $\mathrm{pH}$ in seawater, but also the $\delta^{11} \mathrm{~B}$ value in water from which it precipitates, it is important to have seawater $\delta^{11} \mathrm{~B}$ constraints in order to verify the boron isotopic composition for culture experiments. In addition, other isotopic composition such as ${ }^{87} \mathrm{Sr} /{ }^{86} \mathrm{Sr}$ may be needed to clarify the water sources influencing the marine environment.

\section{CONCLUSIONS}

In this study, we developed a rapid and high-throughput microsublimation method to purify boron from alkaline matrices and organic matter. The advantage of our method is that it provides a consistent, steady heating and cooling environment for a large quantity of samples. Several tests have confirmed the viability of our technique, including comparisons of results from additional $\mathrm{H}_{2} \mathrm{O}_{2}$ treatment and applying the microsublimation method alone, different sublimation times, and quantitative recovery tests using standard addition (e.g. Foster et al. ${ }^{[36]}$ ). Based on these assessments, our microsublimation technique provides a low-blank method for the quantitative recovery and separation of boron from both major elements and organic matter. No further resins or $\mathrm{H}_{2} \mathrm{O}_{2}$ treatment are required. Coupling the new microsublimation technique with the TENTIMS method, a reproducibility better than 1.4\% (2 STD, $n>10$ ) was achieved for a variety of standards with a wide range of boron isotopic ratios, including boric acid standards SRM 951a and AE-121, seawater standard IAEA B-1, and an in-house coral standard UM-CP1. Furthermore, a sample size $<1 \mathrm{ng}$ is required for each measurement, which is sufficient for reconstructing high-resolution geological records. The preliminary test on natural seawater also showed comparable precision with measurements on standards, confirming the applicability of our high-precision boron isotopic analysis by TE-NTIMS.

\section{SUPPORTING INFORMATION}

Additional supporting information may be found in the online version of this article.

\section{Acknowledgements}

Funding for this project was provided by the University of Michigan's Rackham Graduate School, the Department of Earth and Environmental Science, and the Sigma Xi Scientific Society through grants to Y. -W. Liu. Paul Tomascak is thanked his analytical assistance.

\section{REFERENCES}

[1] M. Berglund, M. E. Wieser. Isotopic compositions of the elements 2009 (IUPAC Technical Report). Pure Appl. Chem. 2011, 83, 397.

[2] B. Chetelat, C. Q. Liu, J. Gaillardet, Q. L. Wang, Z. Q. Zhao, C. S. Liang, Y. K. Xiao. Boron isotopes geochemistry of the Changjiang basin rivers. Geochim. Cosmochim. Acta 2009, 73,6084 .

[3] D. Lemarchand, J. Gaillardet. Transient features of the erosion of shales in the Mackenzie basin (Canada), evidences from boron isotopes. Earth Planet. Sci. Lett. 2006, 245,174 . 
[4] Y.-C. Liu, C.-F. You, K.-F. Huang, R.-M. Wang, C.-H. Chung, H.-C. Liu. Boron sources and transport mechanisms in river waters collected from southwestern Taiwan: Isotopic evidence. J. Asian Earth Sci. 2012, 58, 16.

[5] B. Chetelat, J. Gaillardet, R. Freydier. Use of B isotopes as a tracer of anthropogenic emissions in the atmosphere of Paris, France. Appl. Geochem. 2009, 24, 810.

[6] A.-D. Schmitt, N. Vigier, D. Lemarchand, R. Millot, P. Stille, F. Chabaux. Processes controlling the stable isotope compositions of $\mathrm{Li}, \mathrm{B}, \mathrm{Mg}$ and $\mathrm{Ca}$ in plants, soils and waters: A review. Compt. Rendu. Geosci. 2012, 344, 704.

[7] M. Scambelluri, S. Tonarini. Boron isotope evidence for shallow fluid transfer across subduction zones by serpentinized mantle. Geology 2012, 40, 907.

[8] E. Douville, M. Paterne, G. Cabioch, P. Louvat, J. Gaillardet, A. Juillet-Leclerc, L. Ayliffe. Abrupt sea surface $\mathrm{pH}$ change at the end of the Younger Dryas in the central subequatorial Pacific inferred from boron isotope abundance in corals (Porites). Biogeoscience 2010, 7, 2445.

[9] G. L. Foster. Seawater $\mathrm{pH}, \mathrm{pCO}_{2}$ and $\left[\mathrm{CO}_{3}^{2-}\right]$ variations in the Caribbean Sea over the last 130 kyr: A boron isotope and B/ Ca study of planktic foraminifera. Earth Planet. Sci. Lett. 2008, 271, 254.

[10] B. Hönisch, N. G. Hemming. Surface ocean $\mathrm{pH}$ response to variations in pCO2 through two full glacial cycles. Earth Planet. Sci. Lett. 2005, 236, 305.

[11] C. Pelejero, E. Calvo, M. T. McCulloch, J. F. Marshall, M. K. Gagan, J. M. Lough, B. N. Opdyke. Preindustrial to modern interdecadal variability in coral reef $\mathrm{pH}$. Science 2005, 309, 2204.

[12] N. G. Hemming, G. N. Hanson. Boron isotopic composition and concentration in modern marine carbonates. Geochim. Cosmochim. Acta 1992, 56, 537.

[13] A. Sanyal, N. G. Hemming, G. N. Hanson, W. S. Broecker. Evidence for a higher $\mathrm{pH}$ in the glacial ocean from boron isotopes in foraminifera. Nature 1995, 373, 234.

[14] N. G. Hemming, G. N. Hanson. A procedure for the isotopic analysis of boron by negative thermal ionization mass spectrometry. Chem. Geol. 1994, 114, 147.

[15] D. Lemarchand, J. Gaillardet, E. Lewin, C. J. Allegre. The influence of rivers on marine boron isotopes and implications for reconstructing past ocean $\mathrm{pH}$. Nature 2000, 408, 951.

[16] G. L. Foster, P. A. E. Pogge von Strandmann, J. W. B. Rae. Boron and magnesium isotopic composition of seawater. Geochem. Geophys. Geosyst. 2010, 11, Q08015.

[17] H. Kakihana, M. Kotaka, S. Satoh, M. Nomura, M. Okamoto. Fundamental studies on the ion-exchange separation of boron isotopes. Bull. Chem. Soc. Jpn. 1977, 50, 158.

[18] B. Hönisch, N. G. Hemming, A. G. Grottoli, A. Amat, G. N. Hanson, J. Bijma. Assessing scleractinian corals as recorders for paleo-pH: Empirical calibration and vital effects. Geochim. Cosmochim. Acta 2004, 68, 3675.

[19] K. Klochko, A. J. Kaufman, W. Yao, R. H. Byrne, J. A. Tossell. Experimental measurement of boron isotope fractionation in seawater. Earth Planet. Sci. Lett. 2006, 248, 276.

[20] M. Pagani, D. Lemarchand, A. Spivack, J. Gaillardet. A critical evaluation of the boron isotope-pH proxy: The accuracy of ancient ocean $\mathrm{pH}$ estimates. Geochim. Cosmochim. Acta 2005, 69, 953.

[21] B. Hönisch, N. G. Hemming, D. Archer, M. Siddall, J. F. McManus. Atmospheric carbon dioxide concentration across the mid-Pleistocene Transition. Science 2009, 324, 1551.

[22] P. N. Pearson, M. R. Palmer. Middle Eocene seawater $\mathrm{pH}$ and atmospheric carbon dioxide concentrations. Science 1999, 284, 1824.
[23] J. Trotter, P. Montagna, M. McCulloch, S. Silenzi, S. Reynaud, G. Mortimer, S. Martin, C. Ferrier-Pagès, J.-P. Gattuso, R. Rodolfo-Metalpa. Quantifying the $\mathrm{pH}$ 'vital effect' in the temperate zooxanthellate coral Cladocora caespitosa: Validation of the boron seawater $\mathrm{pH}$ proxy. Earth Planet. Sci. Lett. 2011, 303, 163.

[24] J. W. B. Rae, G. L. Foster, D. N. Schmidt, T. Elliott. Boron isotopes and $\mathrm{B} / \mathrm{Ca}$ in benthic foraminifera: Proxies for the deep ocean carbonate system. Earth Planet. Sci. Lett. 2011, 302, 403.

[25] E. Anagnostou, K. F. Huang, C. F. You, E. L. Sikes, R. M. Sherrell. Evaluation of boron isotope ratio as a $\mathrm{pH}$ proxy in the deep sea coral Desmophyllum dianthus: Evidence of physiological pH adjustment. Earth Planet. Sci. Lett. 2012, 349-350, 251.

[26] S. Krief, E. J. Hendy, M. Fine, R. Yam, A. Meibom, G. L. Foster, A. Shemesh. Physiological and isotopic responses of scleractinian corals to ocean acidification. Geochim. Cosmochim. Acta 2010, 74, 4988.

[27] S. Reynaud, N. G. Hemming, A. Juillet-Leclerc, J.-P. Gattuso. Effect of $\mathrm{pCO}_{2}$ and temperature on the boron isotopic composition of the zooxanthellate coral Acropora sp. Coral Reefs 2004, 23, 539.

[28] S. Reynaud, C. Rollion-Bard, S. Martin, R. Rolopho-Metalpa, J.-P. Gattuso. Effect of elevated $\mathrm{pCO}_{2}$ on the boron isotopic composition into the Mediterranean scleractinian coral Cladocora caespitosa. CIESM Workshop Monographs 2008, 36,71 .

[29] C. Pelejero, E. Calvo, O. Hoegh-Guldberg. Paleo-perspectives on ocean acidification. Trends Ecol. Evol. 2010, 25, 332.

[30] N. Allison, A. A. Finch. $\delta^{11} \mathrm{~B}, \mathrm{Sr}, \mathrm{Mg}$ and $\mathrm{B}$ in a modern Porites coral: the relationship between calcification site $\mathrm{pH}$ and skeletal chemistry. Geochim. Cosmochim. Acta 2010, 74, 1790.

[31] S. A. Kasemann, D. N. Schmidt, J. Bijma, G. L. Foster. In situ boron isotope analysis in marine carbonates and its application for foraminifera and palaeo-pH. Chem. Geol. 2009, 260, 138 .

[32] D. Lemarchand, J. Gaillardet, C. Göpel, G. Manhès. An optimized procedure for boron separation and mass spectrometry analysis for river samples. Chem. Geol. 2002, $182,323$.

[33] Y. Liu, W. Liu, Z. Peng, Y. Xiao, G. Wei, W. Sun, J. He, G. Liu, C.-L. Chou. Instability of seawater $\mathrm{pH}$ in the South China Sea during the mid-late Holocene: Evidence from boron isotopic composition of corals. Geochim. Cosmochim. Acta 2009, 73, 1264.

[34] G. Wei, M. T. McCulloch, G. Mortimer, W. Deng, L. Xie. Evidence for ocean acidification in the Great Barrier Reef of Australia. Geochim. Cosmochim. Acta 2009, 73, 2332.

[35] S. Barth. Boron isotopic analysis of natural fresh and saline waters by negative thermal ionization mass spectrometry. Chem. Geol. 1997, 143, 255.

[36] G. L. Foster, Y. Ni, B. Haley, T. Elliott. Accurate and precise isotopic measurement of sub-nanogram sized samples of foraminiferal hosted boron by total evaporation NTIMS. Chem. Geol. 2006, 230, 161.

[37] Y. Ni, G. L. Foster, T. Elliott. The accuracy of $\delta^{11} \mathrm{~B}$ measurements of foraminifers. Chem. Geol. 2010, 274, 187.

[38] A. S. Al-Ammar, R. K. Gupta, R. M. Barnes. Elimination of boron memory effect in inductively coupled plasma-mass spectrometry by ammonia gas injection into the spray chamber during analysis. Spectrochim. Acta, Part B 2000, 55, 629.

[39] P. Louvat, J. Bouchez, G. Paris. MC-ICP-MS isotope measurements with direct injection nebulisation (d-DIHEN): Optimisation and application to boron in seawater and carbonate samples. Geostand. Geoanal. Res. 2010, 35, 75. 
[40] R. N. Sah, P. H. Brown. Boron determination, a review of analytical methods. Microchem. J. 1997, 56, 285.

[41] J. Gaillardet, D. Lemarchand, C. Göpel, G. Manhès. Evaporation and sublimation of boric acid: Application for boron purification from organic rich solutions. Geostand. Newslett. 2001, 25, 67.

[42] B.-S. Wang, C.-F. You, K.-F. Huang, S.-F. Wu, S. K. Aggarwal, C.-H. Chung, P.-Y. Lin. Direct separation of boron from Naand Ca-rich matrices by sublimation for stable isotope measurement by MC-ICP-MS. Talanta 2010, 82, 1378.

[43] E. C. Beirne, A. D. Wanamaker Jr, S. C. Feindel. Experimental validation of environmental controls on the $\delta^{13} \mathrm{C}$ of Arctica islandica (ocean quahog) shell carbonate. Geochim. Cosmochim. Acta 2012, 84, 395.

[44] D. R. Kester, I. W. Duedall, D. N. Connors, R. M. Pytkowicz. Preparation of artificial seawater. Limnol. Oceanogr. 1967, 12, 176.

[45] R. Gonfiantini, S. Tonarini, M. Gröning, A. Adorni-Braccesi, A. S. Al-Ammar, M. Astner, S. Bächler, R. M. Barnes, R. L. Bassett, A. Cocherie, A. Deyhle, A. Dini, G. Ferrara, J. Gaillardet, J. Grimm, C. Guerrot, U. Krähenbühl, G. Layne, D. Lemarchand, A. Meixner, D. J. Northington, M. Pennisi, E. Reitznerová, I. Rodushkin, N. Sugiura, R. Surberg, S. Tonn, M. Wiedenbeck, S. Wunderli,
Y. Xiao, T. Zack. Intercomparison of boron isotope and concentration measurements. Part II: Evaluation of results. Geostand. Newslett. 2003, 27, 41.

[46] S. Kasemann, A. Meixner, A. Rocholl, T. Vennemann, M. Rosner, A. K. Schmitt, M. Wiedenbeck. Boron and oxygen isotope composition of certified reference materials NIST SRM 610/612 and reference materials JB-2 and JR-2. Geostand. Newslett. 2001, 25, 405.

[47] A. Vengosh, Y. Kolodny, A. Starinsky, A. R. Chivas, M. T. McCulloch. Coprecipitation and isotopic fractionation of boron in modern biogenic carbonates. Geochim. Cosmochim. Acta 1991, 55, 2901.

[48] J. Vogl, M. Rosner. Production and certification of a unique set of isotope and delta reference materials for boron isotope determination in geochemical, environmental and industrial materials. Geostand. Geoanal. Res. 2012, 36, 161.

[49] H. Stoll, G. Langer, N. Shimizu, K. Kanamaru. B/Ca in coccoliths and relationship to calcification vesicle $\mathrm{pH}$ and dissolved inorganic carbon concentrations. Geochim. Cosmochim. Acta 2012, 80, 143.

[50] S. Barker, M. Greaves, H. Elderfield. A study of cleaning procedures used for foraminiferal $\mathrm{Mg} / \mathrm{Ca}$ paleothermometry. Geochem. Geophys. Geosyst. 2003, 4. 